\title{
Flore microbienne du lait pasteurisé de la région de Téhéran
}

\author{
par \\ G. KARIM et M. Z. MOUSAVI*
}

\section{INTRODUCTION}

Faisant suite à notre contribution à l'étude de la flore bactérienne du lait cru de la région de Téhéran [2, 4], nous avons étudié la flore microbienne du lait pasteurisé en même temps que l'influence $\mathrm{du}$ traitement thermique (pasteurisation HTST) sur la flore du lait cru d'origine.

Anderson et Meanwell [8, 9, 10] ont pu conclure que la durée de conservation du lait provenant de fermes où l'hygiène est respectée est prolongée après pasteurisation. Ils ont conclu également qu'en ajoutant, avant pasteurisation, un pourcentage de lait cru provenant des fermes "non hygiéniques ", on diminue la durée de conservation du lait pasteurisé. Ashton [8] a montré que par suite de la conservation du lait cru à $4^{\circ} \mathrm{C}-10^{\circ} \mathrm{C}$ pendant $24 \mathrm{~h}$ avant pasteurisation, l'hydrolyse enzymatique dans le lait pasteurisé est accrue en raison de la flore microbienne.

Glenn [7] a montré que le nombre et la caractéristique des germes microbiens qui se trouvent dans le lait cru ont une influence sur la saveur du lait après pasteurisation.

\section{MATERIEL ET METHODES}

Nous avons prélevé au total 80 échantillons à partir des tanks de garde du lait pasteurisé à la Centrale laitière de Téhéran.

Le prélèvement était effectué stérilement et des échantillons étaient transportés dans de la glace au laboratoire, puis examinés. A

* Département de l'Hygiène Alimentaire, Université de Téhéran, B.P. 3262, Téhéran (Iran). 
partir de chaque échantillon, nous avons effectué une numération totale selon la norme internationale FIL/IDF 3 : 1958. A partir de chaque boîte contenant entre 30 et 300 colonies, nous avons choisi au hasard 10 colonies, à partir desquelles nous avons ensemencé des tubes de gélose nutritive qui ont été incubés à $30^{\circ} \mathrm{C}$ pendant $24 \mathrm{~h}$. A partir de ces tubes, nous avons ensemencé, avec une anse de platine, une boîte de Petri contenant de la gélose nutritive, additionnée de 10 p. 100 de lait écrémé, puis après $24-28 \mathrm{~h}$ d'incubation à $30^{\circ} \mathrm{C}$, nous avons prélevé une colonie bien isolée et avons coloré par la méthode de Gram. Après 48-72 h d'incubation [7] de la culture purifiée, les bâtonnets Gram + sont colorés avec du méthyl-violet pour la différenciation des spores. L'épreuve à la catalase sur lame a été effectuée en mélangeant un peu de la culture de la boîte dans une goutte d'eau oxygénée à 10 volumes. Les bâtonnets Gram - sont mis en bouillon Mc Conkey et, après $72 \mathrm{~h}$ d'incubation à $30^{\circ} \mathrm{C}$, la production d'acide et de gaz a été vérifiée. D'après les résultats obtenus et en utilisant le diagramme suivant, nous avons identifié les bactéries.

\section{Culture purifiée}

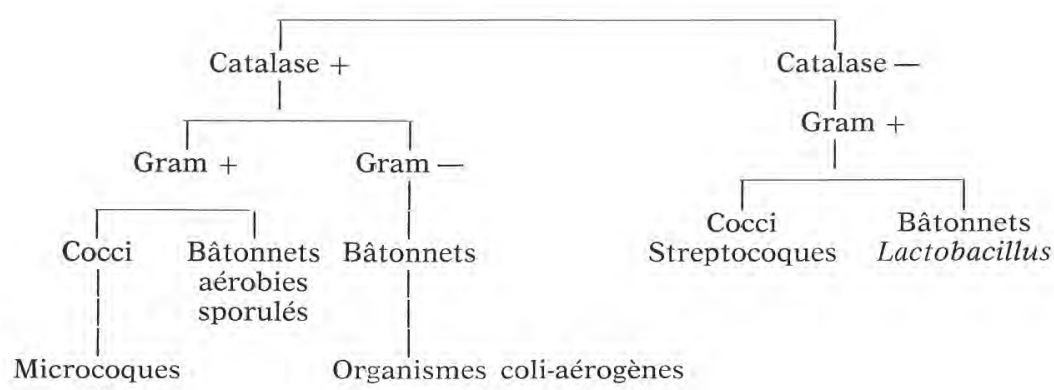

\section{RESULTATS ET DISCUSSION}

Le tableau 1 montre les résultats de la numération totale. Sur 80 échantillons examinés, 16 échantillons (20 p. 100) donnaient une numération totale de l'ordre de $1 \times 10^{4}-3 \times 10^{4}$, ce qui est d'excellente qualité selon la classification dans la norme nationale [3].

Le reste des échantillons $(42,5$ p. 100) donnaient une numération totale de $9 \times 10^{4}$ à $3 \times 10^{5}$; ce qui dépasse la norme.

Pour 80 échantillons de lait pasteurisé, nous avons fait au total 680 ensemencements. Le tableau 2 montre la distribution des différents germes rencontrés.

D'après le tableau 2 les 16 échantillons qui étaient classés « qualité excellente $\left(\mathrm{NT}=1 \times 10^{4}-3 \times 10^{4}\right)$ " possédaient une flore 
TABLEAU 1

Résultat de la numération totale

\begin{tabular}{|c|c|c|c|c|}
\hline \multirow{2}{*}{$\mathrm{NT} / \mathrm{ml}$} & \multicolumn{2}{|c|}{$\begin{array}{c}\text { Nombre d'échantillons } \\
\text { et p. } 100\end{array}$} & \multicolumn{2}{|c|}{$\begin{array}{l}\text { Nombre de cultures } \\
\text { et p. } 100\end{array}$} \\
\hline & Nombre & p. 100 & Nombre & p. 100 \\
\hline $1 \times 10^{4}-3 \times 10^{4}$ & 16 & 26 & 155 & 22,7 \\
\hline$>3 \times 10^{4}-6 \times 10^{4}$ & 24 & 30 & 195 & 28,6 \\
\hline$>6 \times 10^{4}-9 \times 10^{4}$ & 6 & 7,5 & 49 & 7,2 \\
\hline$>9 \times 10^{4}-3 \times 10^{5}$ & 34 & 42,5 & 281 & 41 \\
\hline Total & 80 & 100 & 680 & 99,5 \\
\hline
\end{tabular}

microbienne dont 78 p. 100 des micro-organismes dominants sur 155 cultures étaient constitués par des microcoques [1,5]. Les microcoques formaient également la flore dominante dans les 244 cultures de lait donnant un NT de $>3 \times 10^{4}-9 \times 10^{4}$ et les 281 cultures de lait avec un NT de $>9 \times 10^{4}-3 \times 10^{5}$; dans tous les échantillons, les bactéries Gram + non sporulées et Gram + sporulées étaient les plus nombreuses après les microcoques. D'une façon générale et en ne tenant pas compte de la numération totale, sur 680 cultures effectuées, la flore dominante était constituée de microcoques (71,3 p.100) G + puis les bactéries non sporulées Gram + (20,2 p.100) et des bactéries $\mathrm{G}+$ sporulées $(8,3$ p. 100) [6].

\section{CONCLUSION}

Il apparaît, en résumé, que la qualité microbiologique finale et la durée de conservation du lait pasteurisé dépend bien de l'hygiène au cours des opérations d'obtention, de conservation et de transport du lait cru.

La désinfection rigoureuse des appareils par les désinfectants et les détergents ainsi que l'éducation du personnel sont également nécessaires pour l'obtention d'une prolongation de la durée de conservation du lait pasteurisé. 
TABLEAU 2

Distribution des différents germes

\begin{tabular}{|c|c|c|c|c|c|c|c|c|c|c|}
\hline \multirow{2}{*}{ Micro-organismes } & \multicolumn{2}{|c|}{$1 \times 10^{4}-3 \times 10^{4}$} & \multicolumn{2}{|c|}{$3 \times 10^{4}-6 \times 10^{4}$} & \multicolumn{2}{|c|}{$6 \times 10^{4}-9 \times 10^{4}$} & \multicolumn{2}{|c|}{$9 \times 10^{4}-3 \times 10^{5}$} & \multicolumn{2}{|c|}{$\begin{array}{c}\text { Total } \\
680\end{array}$} \\
\hline & Nombre & p. 100 & Nombre & p. 100 & Nombre & p. 100 & Nombre & p. 100 & Nombre & p. 100 \\
\hline Microcoques & 121 & 78 & 147 & 75,3 & 34 & 69,3 & 183 & 65,1 & 485 & 71,3 \\
\hline Bactéries Gram + non sporulées & 20 & 12,9 & 28 & 14,3 & 11 & 22,4 & 79 & 28,1 & 138 & 20,2 \\
\hline Bactéries Gram + sporulées & 14 & 9 & 20 & 10 & 4 & 8 & 10 & 6,7 & 57 & 8,3 \\
\hline
\end{tabular}




\section{Rés u mé}

80 échantillons de lait pasteurisé ont été examinés pour la détermination de sa flore dominante. La flore microbienne des échantillons était représentée par des microcoques (71,3 p.100), des bactéries non sporulées Gram + (20 p.100) et des bâtonnets sporulés Gram + $(8,3$ p. 100$)$.

\section{S u m m a ry}

\section{THE MICROFLORA OF PASTEURISED MILK IN TEHRAN AREA}

A total of 80 samples of pasteurised milk was examined for determination of the dominant organisms of the microflora. $680 \mathrm{cul}$ tures were made from the samples which 71,3 p. 100 of them were micrococci instead of 20,8 p. 100 Gram + non sporeforming rods and from 8,3 p. 100 of the cultures $\mathrm{G}+$ sporeforming rods were isolated.

\section{Bibliographie}

[1] Credit (C.), Hedeman (R.), Heywood (P.) and Westoff (D.) (1972). - Identification of bacteria isolated from pasteurised milk following refrigerated storage. J. Milk Food Technol., 35 (12).

[2] FARKHONDEH (A.) (1974). - Aerobic sporeforming microorganisms in the mixed milk of Tehran area. XIX International Dairy Congress India, vol. $1 \mathrm{E}$.

[3] Institute of Standards and Industrial Research of Iran. ISIR No. 93-1344.

[4] KaRim (G.) et Kachani (Gh.) (1978). - Flore bactérienne du lait cru de la région de Téhéran. Le Lait, 573-574.

[5] MaXcY (R. B.) (1976). - Nature and growth response of the microflora of pasteurized, packaged milk. J. Milk, Food Technol., 30, 213-218.

[6] Shehata (T. E.), Duran (A.) and Collins (E. B.) (1971). - Influence of temperature on the growth of psychrophilic strains of bacillus. J. Dairy Sci., 54, 1574-1582.

[7] Thomas (W. R.), Reinbold (G. W.) and Nelson (F. E.) (1963). - The effect of temperature and time of plate incubation on the enumeration of pasteurisation-resistant bacteria in milk. J. Milk, Food Technol., 26, 357-360.

[8] Thomas (S. B.) and Druce (R. G.) (1969). - Psychrotrophic bacteria in refrigerated pasteurised milk, part 1. Dairy Industries, 34 (6).

[9] Thomas (S. B.) and Druce (R. G.) (1969). - Psychrotrophic bacteria in refrigerated pasteurised milk, part 2. Dairy Industries, 34 (7).

[10] Thomas (S. B.) and Druce (R. G.) (1969). - Psychrotrophic bacteria in refrigerated pasteurised milk, part 3. Dairy Industries, 34 (8). 